Bol. Acad. peru. leng. 50. 2010 (225-232)

\title{
ALGUNOS BUENOS LIBROS DEL 2009
}

\author{
Carlos Eduardo Zavaleta
}

Academia Peruana de la Lengua

Fecha de recepción:

El año 2010 está aún por la mitad, pero yo recuerdo todavía algunos buenos libros del año previo, el 2009. Eso sí, desde el comienzo debo decir que ésta no es una nota bibliográfica, género en verdad tan respetable como otros, pero quizá aquí muy descuidado o relegado, en vez de ser puntual y minucioso.

Recuerdo, por ejemplo, que en la edición de nuestra ya lejana revista generacional Letras peruanas (1951-1964), dirigida por Jorge Puccinelli, los entonces jóvenes escritores nos iniciamos casi obligatoriamente trabajando en la sección "Entre libros", título tomado de Alfonso Reyes y que encabezaba nuestro florilegio de notas. Hoy releo los nombres de Alberto Escobar, Wàshington Delgado, Abelardo Oquendo, Víctor Li Carrillo, Manuel Jesús Baquerizo, incluso el mío propio, o el de aquel periodista Fernández Arce, quien se fue a vivir por décadas a China. I labia inclusive cierto honor en empezar por abajo.

Ahora veo sobre el escritorio unos valiosos libros del 2009, que o bien no han merecido el debido elogio, o han sido olvidados en tan corto lapso, 
o quizá hayan sido recordados, pero sólo por el título, como si el nombre fuese suficiente entre nuestros memoriosos.

Miremos, por ejemplo, algunos de ellos. ¿Es posible no honrar la Obra completa (Lima, 4 vols, Universidad de Lima), del poeta y ensayista Wàshington Delgado, cuyo solo nombre condensa la vastedad de temas y estructuras que se dieron, ricas y notables, en la generación de los años cincuenta, además de la obra ensayística de ese autor, y aun de sus prosas intermedias, como sus "Bagatelas", publicadas en El Comercio, El recopilador y antólogo aquí es nada menos que Jorge Eslava, poeta y docente, quien se ha dedicado años a esa obra, y sobre todo empeñado en convencer a una universidad limeña, la suya, que carece de una Facultad de Letras, pero no de una visión humanista y literaria. Pues sí, Jorge Eslava ha obtenido ese notable y extraño respaldo, y merced a él debemos estos cuatro bellos volúmenes (El corazón es fuego, obra poética; Monologo del habitante, cuentos y artículos culturales; Oficio y conducta, tratados de literatura española y peruana; y Para vivir mañana, ensayos y conferencias de literatura). Si algo faltaba en la obra irradiante de Delgado, es justamente una publicación amplia y ceñida al mismo tiempo.

En segundo lugar, puesto tan valioso como el primero, pondremos un volumen arriesgado y novedoso en sus fines, como el titulado ;Usted fue aprista! Bases para una historia crítica del APRA, por el ensayista político Nelson Manrique (Lima, Univ. Católica, 2009), pues pretende no sólo urdir una historia política del partido político dicho, columna vertebral de un vasto estudio sobre los problemas sociales del país, a partir de los años treinta, empezando por la historia misma de ese partido, sino que avanza sobre la llamada "revolución” de Velasco Alvarado, la cual, según el autor, fue el más ambicioso proyecto revolucionario del Perú en el siglo XX, y todavía nos ofrece algo más, un doble panorama de consecuencias o conclusiones, pues él juzga que su estudio debe fijar no sólo los hechos mismos, sino su "representación" o su "imaginario", afín a los grandes sucesos sociales, que los envuelve ("el fantasma de la revolución”), como en un doble significado social. 
Sí, la historia corre por dos cursos que se superponen o aíslan, pues sus efectos no son los mismos, y a veces tales "representaciones" son tan fuertes que incluso pueden moldear, facilitar, o retrasar, o impedir, la aceptación de los nuevos hechos, digo, la comprensión de ellos, de esos cambios históricos que tantas veces necesitamos, pero que no vemos realizarse.

Tamaña empresa está llena de lucidez, pero también de valentía para hurgar temas palpitantes y colaterales, que incluso tocan carne viva, pues así lo siente el lector peruano de a pie, cuando el país sufre y se trastorna, y espera a que el famoso "destino nacional" se cumpla de una vez, y no se tuerza de nuevo por el camino.

Veamos a continuación la valiosa edición crítica de la Primera Serie de las Tradiciones peruanas del notable Ricardo Palma, hecha por Pedro Díaz Ortiz, laborioso crítico, cuyo cálido hogar sigue siendo la misma universidad que lleva con orgullo el nombre de nuestro primer tradicionista. Tantas décadas pasadas, tantos brillantes ensayos sobre aquél, desde Riva-Agüero y Porras, hasta Alberto Escobar, y todavía faltaba esta edición crítica que ayudará mucho para asediar el estilo, la esencia, y los vínculos con la historia, y por fin el estudio del invento mismo, y la maestría del género modelado por el impar maestro. Le deseamos suerte al colega Pedro Díaz Ortiz en la publicación de las nuevas series, y ojalá siga mereciendo el apoyo de la mismas universidad.

También en el 2009 se publicó entre nosotros la primera edición facsimilar de Comentarios Reales del Inca Garcilaso de la Vega, replicando la edición príncipe de los Comentarios Reales, (Lisboa, en la oficina de Pedro Crasbeck, año de MDCIX), libro que a su vez, según dicen sus editores Miguel Ángel Rodríguez Rea y Ricardo Silva Santisteban, "ha atravesado indemne cuatro siglos, admirado y apreciado por todos como una de las obras cumbres de la lengua castellana, la que con supremacía impera en nuestro país, y que constituye testimonio tan importante de nuestros orígenes y de nuestra escritura", según reza el prólogo de tan esperado libro. En la edición han colaborado tres instituciones, la Academia Peruana de la Lengua, la Biblioteca Nacional del Perú, y la Universidad 
Ricardo Palma. Buena ocasión ésta en que ojalá se difunda tal libro en los principales entes culturales del país, y así las nuevas generaciones acceden más fácilmente que nosotros a dichas fuentes ineludibles. O sea que ya tenemos nuestra propia edición peruana de Garcilaso, junto con otra tan valiosa como fue la del "Quijote", publicada en Lima, en 1992, editada por don Aurelio Miró Quesada y con los dibujos del pintor Fernando de Szyszlo, en conmemoración del cuarto centenario del descubrimiento europeo de América.

Varios capítulos del libro de Garcilaso se comentaron enseguida en el número 9, de diciembre del 2009, de la Revista de la Facultad de Humanidades y Lenguas Modernas, de la ya predicha universidad palmista. Ahí, asimismo, se recuerdan las muertes en Lima, a fines de 1969, de dos valiosas figuras culturales, como José María Arguedas y Honorio Delgado, por más que esta costumbre de juntar personas por casualidad de decesos quizá no conduzca a mucho. Mejor fruto produce ver en la misma revista, un ensayo sobre el insigne Edgar Alian Poe, cuya obra fue traducida por el no menos insigne Julio Cortázar, el autor vanguardista más celebrado en América Latina. Esa “dupla”, es admirablemente popular entre los jóvenes de América y Europa.

Pero quizá junto a este amable recuerdo, valga asimismo señalar otro artículo de la misma revista, el de Julio Calvo Pérez sobre "Los préstamos del quechua al español, entre el lenguaje cotidiano y literario". He ahí un tema valioso, la riqueza de nuestra lengua madre, abrazando la nueva.

Prosigamos. Debemos subrayar especialmente la aparición de dos nutridos tomos, titulados Cuento y Poesía, dos antologías dedicadas al Perú y Ecuador durante los años 1998-2008, esta década en que finalmente, luego de repetidos episodios bélicos, signados por la desconfianza y el recelo, celebramos al fin una paz que debió existir desde nuestra Independencia. Tales tomos son admirables no sólo por su seriedad y belleza editorial, sino por ser prolijos, incisivos, exigentes, con esa producción literaria en dos países que no se habían estudiado nunca juntos, sino siempre separados. Soy testigo de que los antólogos, 
Gabriela Falconí y Carlos Yushimito del Valle (cuento) y Karina Marín y Carlos Villacosta (poesía) culminaron este Utilísimo proyecto cultural, que ojalá se repita en casos similares.

No menos interesante es la Antología general de la traducción en el Perú (Univ. Católica, 2009) cuyo tomo IV (el único que he visto) se dedica a la narrativa del siglo XX. Su recopilador es nada menos que nuestro habitual especialista, Ricardo Silva Santisteban. En sus nutridas páginas celebramos, por ejemplo, el texto de un fabliaux del siglo XII, traducido por Sebastián Salazar Bondy; un cuento chino, por Feng Menlong, vertido por Guillermo Dañino; el magnético y espléndido cuento "Wakefield", de Nathaniel Hawthorne, que nos ofrece Luis Loayza, mientras Tomás Escajadillo nos traduce "El barril del amontillado", de Poe. Manuel Beltroy, el enciclopédico, vertió la famosa "Leyenda de San Juan Hospitalario", de Gustave Flaubert; Julio Ramón Ribeyro se deleitó con "Paseo campestre", de Maupassant; Mario Vargas Llosa, en sus años mozos, hizo lo propio con "Un corazón bajo la sotana", de Rimbaud; José Carlos Mariátegui, con "El banco bajo el viejo ciprés", de Pirandello. De César Vallejo, menudo traductor, vemos aquí un capítulo del "Hombre nuevo", de Barbusse; el filósofo Carlos Cuetro Fernandini fue buen lector de Rilke, de quien nos ofrece "De cómo murió cantando el anciano Timofei". Sigamos expurgando la selección. Aquí vemos a Alfonso La Torre apegado a E.M. Forster y al texto de "El otro lado del seto"; Javier Heraud nos sorprende con su versión de "Las hermanas", sutil cuento de Joyce; incluso Kafka está aquí con el cuento "El médico rural”, que nos entrega José del Solar; asimismo, Ventura García Calderón, traduciéndose a sí mismo, en "La imprudencia de ser médico"; y de nuevo, sorprendidos, hallamos a Katherine Mansfield, exquisita cuentista, en la versión de "La mosca", por Alberto Puertas; y nos damos, asimismo, con el bello "El sueño del pongo", de Arguedas, mientras Guillermo Niño de Guzmán nos da los primeros capítulos originales de The Sun Also Rises, de Hemingway, digo, h )S textos suprimidos por influjo de Fitzgerald; y aun yo mismo me veo ahí, traduciendo las sombras del cuento "Una rosa para Emily", de Faulkner. Casi nadie falta. Ahí está Luis Alberto Sánchez, quien tradujo muchos libros, por ejemplo, La esperanza, novela de André Malraux, que no le salió mal, pero sí falló de veras en su versión de Dublineses, de Joyce. 
En fin, aparte de tales textos, hay una gruesa bibliografía que cierra el libro y da los menudos títulos completos, traducidos por cada autor. Valioso tomo en verdad, demostrativo no sólo de la perspicacia y tesón del antólogo Silva Santisteban, sino del amor de cada autor por su par lejano, de cada uno con esa otra alma, allende los mares, con quien creció y entró en la magia de la literatura.

También hay otros libros cuya importancia es innegable por sí mismos, lo que debiera ser un ejemplo para nuestros escritores. En ese nivel veo, o vimos, a Luis Loayza, a quien se ha dedicado justamente el bello volumen Para leer a Loayza, antología reunida por César Ferreira y Américo Mudarra (Lima, Ediciones del Vicerrectorado Académico de la Universidad Nacional Mayor de San Marcos). Pocas veces tantos autores peruanos han rendido un homenaje rico en matices, pues inclusive la brevedad y sutileza de los textos de Loayza, divididos aquí en los dedicados a los "cuentos" y a la novela "Una piel de serpiente", y a los varios y selectos ensayos del autor, se prestan el análisis. El volumen constituye una selección de juicios y miradas durante las décadas que corren desde los cincuenta en adelante. El tiempo ha decantado los textos y los autores han coincidido en brindar un merecido homenaje. Sin embargo, digamos claramente que Loayza no escribió propiamente "cuentos", sino estampas, donde la prosa era el objetivo central, la prosa como campo de experiencias y de sutilezas, pero tales escritos no buscaron "temas" ni su desarrollo argumental, ni el "remate", absolutamente necesario en un cuento, sino que a Loayza le bastó siempre la organización y la sonoridad del lenguaje, y aspiró al ensayo como la búsqueda de ideas, cuyo razonamiento se exhibe y él llega a una "conclusión" propia, cuando el autor gana un mirador selecto y distinto del de otros autores.

Por otro lado, creo que la novela "Bombardero. Ground Zero", publicada en setiembre del 2008 fue leída y juzgada sólo en el 2009. Por fin tuvimos en las manos una novela desmedida, experimental, desbocada, lanzándose al vacío de la novedad y de su incesante búsqueda verbal.

Su autor, César Gutiérrez, pega un gran salto entre estilos novísimos y peligrosos, muy audaces, e incluso accede a la lengua de los internautas, 
a la manía o jerga del lenguaje telegráfico e informático, aún deforme, y los alberga en su seno, rico e informal, para cogerlos sin pulimento, pero sí respetando las asperezas ultramodernas, o la propia fealdad supuesta, convirtiéndolos en una herramienta útil para lograr la nueva prosa, ese inmenso contraste del lenguaje "antiguo" con los abismos y precipicios de la burla, el sarcasmo, pero también de las abreviaturas telegráficas o informáticas, y sobre todo, de la imaginación libre, feliz y aun vulgar, pero muy organizada en una estructura sonora, primero, y luego ideológica. Pero sí es valioso también el tiempo histórico en que se vive, el cual ha estallado en las torres simbólicas de Nueva York, y ahora el bombardero toma su venganza, buscando silenciosamente por el aire su nuevo objetivo. Historia y posibilidad se juntan, y aun la burla, lo plebeyo, tienen asidero, y así, el mundo está de cabeza y los nervios del juego y del miedo se juntan y nos abruman, aunque al final el bombardero también toque Santiago de Chuco, imagínese, lector. Libro que es una provocación, y por ello mismo es importante para la literatura.

Nos quedan dos libros más, el Manual de Quechua. Enseñanza, Aprendizaje, de Edilberto Lara Irala, prologado por Luis Jaime Cisneros, y el Canto del cuculí. El huayno, por Efraín Rosales. El primero es también un tomo dedicado a la enseñanza y aprendizaje del quechua. Un tomo que será difundido a nivel nacional por el empuje de la editorial de Esteban Quiroz, tan amigo de las aventuras culturales; el autor culmina aquí su dedicación y respeto a la lengua oriunda del país, cuya difusión durante las últimas décadas necesita de encuestas y estudios selectos que señalen su avance o no, su conocimiento y difusión real.

Y quizá ya era hora de oír la música andina, como en las fiestas de provincia, y así, en ese espíritu jovial, veamos y "oigamos" Canto del cuculí. El huayno. La expresión cultural andina, por Efraín Rosales, recopilador muy apegado a la entraña popular y regional del centro del país, y esta vez enfocado hacia Ancash y el Callejón de Huaylas, a los frutos del "fervor popular en el advenimiento del año nuevo, el cambio y reconocimiento de sus autoridades, los carnavales, la Semana Santa, el Corpus Cristi, los sembríos, las cosechas, las fiestas patronales y los acontecimientos comunales y familiares". Así, entre una larga explicación 
sobre los instrumentos de la región ancashina, nos recuerda inclusive a los cantantes de la zona y nos da algunas canciones oídas desde la infancia, como por ejemplo:

Cien años después de muerto

Comido por los gusanos

Hallarás entre mis huesos

Huellas de haberte querido.

\section{Correspondencia:}

\section{Carlos Eduardo Zavaleta}

Miembro del Consejo Directivo de la Academia Peruana de la Lengua.

Correo electrónico: carlos.eduardo.zavaleta@academiaperuanadelalengua.org 